Military Technical College

Kobry El-Kobbah

Cairo, Egypt

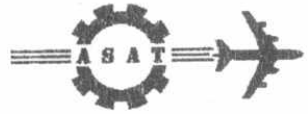

$10^{\text {th }}$ International Conference On Aerospace Sciences\& Aviation Technology

\title{
Mathematical Model Development for Predicting Resistance Forces Exerted on a Single Shank during Earth Cutting.
}

\author{
Mohamed H. M.", Ibrahim A. Elsherif", Hussein M. Mahgoub"', and Shaker M. A."
}

\section{ABSTRACT}

In this paper a study is carried out to develop a mathematical model to predict resisting forces exerted on the single shank during cutting the earth based on the blade geometry parameters, operating conditions and soil parameters. A computer program "SHANK" was made on the basis of this analytical study using a professional mathematical package. A verification was held to the mathematical model using published experimental data resulted from cutting sand using narrow blades and the accompanied operating conditions, tool geometry and soil properties. The comparison between the published results and those predicted by "SHANK" showed that this model can be applied to predict resistance forces exerted upon the single shank during cutting the earth with an acceptable deviation putting into consideration the highly nonlinear behavior of soil.

\section{KEY WORDS}

Earth cutting, soil, off road, soil working machinery, earth moving, terrain and excavation.

\footnotetext{
Graduate student, Egyptian Armed Forces, Cairo, Egypt

** Egyptian Armed Forces, Cairo, Egypt

*.*. Egyptian Armed Forces, Cairo, Egypt

As** Associate professor, Egyptian International Univeristy, Cairo, Egypt
} 


\section{NOMENCLATURE}

$\begin{array}{ll}\Omega_{1} & \text { Lateral rest zone } \\ \Omega_{2} & \text { Frontal rest zone } \\ \Omega_{3} & \text { Uniform motion zone } \\ \Omega_{4} & \text { Rupture surface } \\ a_{1} & \text { Length of single shank } \\ f & \text { Frictional stress } \\ F_{a 1} & \text { Adhesion force between soil and shank surface } \\ F_{f 1} & \text { Friction force between soil and shank surface } \\ F_{r c} & \text { Cohesion force between soil wedge and ground } \\ F_{r f} & \text { Friction force between soil wedge and ground } \\ F_{s c} & \text { Cohesion force on the side of the soil wedge } \\ F_{s f} & \text { Friction force on the side of the soil wedge } \\ G & \text { Lateral pressure on the side of soil wedge } \\ m_{1} & \text { Weight of soil wedge being cut under the ground } \\ \mathrm{p} & \text { Pressure load } \\ \mathrm{P} & \text { Shank force acting on the cutting wedge } \\ \mathrm{Q} & \text { Normal force on the rupture surface } \\ \mathrm{W} & \text { Normal force from effects above the surface }\end{array}$

\section{INTRODUCTION}

Tool shape factors have a considerable effect on earth resistance forces during cutting. Most tillage tool shapes have been developed by cut and try methods or on the basis of qualitative analysis. Mathematical descriptions of shapes are the most versatile means of representation, but tools such as moldboard plows have complex shapes that cannot be easily represented in mathematical form. Graphical representation is often employed for plow bottoms.

The tillage tool design is based on three main factors that control or define the soil manipulation. These factors are initial soil condition, tool shape, and manner of tool movement.

The results of these input factors are evidenced by two output factors, namely, the final soil conditions and the forces required to manipulate the soil. The tool shape concerning design is the surface over which soil moves as tillage tool is operated. The development of studies in each field is demonstrated in the literature review section of the research.

\section{LITERATURE REVIEW}

In this section most of published studies in the fields of interest are covered. McKibben and Reed consoledated the many speed-versus-draft test results reported between 1919 and 1949 [1]. They determine the percent increase in draft as a function of speed.

Nichols and Reed [1] classified the various soil conditions and describe the reactions as shown the following Table 1. 
Table 1 classification of the reactions for the various soil conditions

\begin{tabular}{|l|l|}
\hline Soil type & Reaction \\
\hline Hard cemented soils & $\begin{array}{l}\text { These soils break into large irregular blocks } \\
\text { ahead of the plow, with no definite pattern to the } \\
\text { soil reaction. }\end{array}$ \\
\hline Heavy soils & $\begin{array}{l}\text { Because of the surface reinforcement from the } \\
\text { mass of roots, normal shear planes are not } \\
\text { generally observed, however normal soil } \\
\text { reactions occur below the sod. }\end{array}$ \\
\hline Packed or cemented surface & $\begin{array}{l}\text { This is a rather unusual situation, with relatively } \\
\text { loose soil immediately beneath the packed } \\
\text { surface. Blocks of the surface layer are broken } \\
\text { loose irregularly and lifted like boards. }\end{array}$ \\
\hline Freshly plowed soil & $\begin{array}{l}\text { In this condition the soil has insufficient rigidity } \\
\text { and resistance to compression for the plow to } \\
\text { function properly. }\end{array}$ \\
\hline Push soils & $\begin{array}{l}\text { These soils, when settled, act somewhat like } \\
\text { freshly plowed soil. Adhesion of the soil to the } \\
\text { moldboard builds up a pressure ahead of the } \\
\text { plow bottom, which, because of insufficient } \\
\text { rigidity in the furrow slice, causes the soil to be } \\
\text { pushed to one side rather than being elevated } \\
\text { and turned. }\end{array}$ \\
\hline Normal soil conditions & $\begin{array}{l}\text { The soil has settled and reached a firm condition, } \\
\text { primarily as a result of natural agencies, and is } \\
\text { within proper moisture range for good plowing. }\end{array}$ \\
\hline
\end{tabular}

The influence of different variables upon soil reactions has been investigated in a series of tests made under carefully controlled soil conditions at the USDA's National Tillage Machinery Laboratory [1]. Two soils were used, one a fairly heavy clay loam and the other a fine sandy loam.

C. L. Naiezny [2] analyzed upward cutting, using the theory of perfect plasticity, for every wide blade such as scrapers and for very thin plow blades. The result predicts decreasing soil resistance with increasing blade roughness.

In a companion paper, Bilott, et al [3] reported the results of experiments with an upward cutting vibratory plow.

Yotaro Hatmura and Kenji Chijiwa [4] made an analysis of the mechanism of soil cutting. The distribution of stresses on cutting blade and cutting force in soil cutting were analyzed by experiments.

R.N Yong and Hanna [5] developed the finite element method (F.E.M.) of solution to provide a theoretical means for determination of soil performance under the action of cutting blade and the forces required to promote cutting. M.SPEKTOR [6] studied the principles of soil tool interaction. The study analysed the process of borehole forming in soil through penetration by a conical tool under periodically repeated load impulses. 
M. Spektor and M.Katz [7] presented an experimental study on the frontal resistance forces in soil cutting.

A mathematical model was developed by W. C. Swick and J. V. Perumpral [8] for predicting the resistance forces acting on a narrow blade tillage tools. They used an artificial soil for the test and variable cutting conditions such as cutting speed, cutting depth, and cutting angle.

S. B. Richey et al [9] developed a three dimensional computer graphics technique to describe a moldboard plough surface. An interactive computer program, named PLOW, was developed to show that the computer graphics techniques could be used to represent the tillage tools and then combined with the soil tool mechanics model to calculate the forces exerted by the soil on the tillage tool.

D. C. Suministrado et al [10] determined approximate trajectories of soil furrow subslices and the forces occurring on the moldboard plow surface. The solution of mathematical formula has been facilitated with the aid of the high-speed computers. it was concluded that the calculated total forces approximate the values obtained by experiments at low velocity (about $0.1 \mathrm{~m} / \mathrm{s}$ ) for draft and side draft, while at high velocity (about $0.63 \mathrm{~m} / \mathrm{s}$ ) for the vertical force.

L. Chi and R. L. Kushwaha [11] presented a non-linear 3D finite element model to study the soil failure under a narrow tillage tool. This finite element model takes into account the friction at the soil-tool interface. Results provided soil forces, a progressive developed failure zone, and displacement field and stress distribution along the tool surface.

Yao Yusu and Zeng Dechao [12] found that through analysis of the fundamental behavior of soil - metal friction, a non Newtonian fluid equation could be applied to describe the mechanics of soil -metal friction based on the rate process theory.

Zeng Dechao and Yao Yusu [13] reached to a relationship between soil shear strength as a function of shear rate and normal pressure. They developed a dynamic model for soil cutting resistance predicted by blade and tine taking account of the shear rate effects both on soil shear strength and soil -metal friction, besides the conventional soil slice inertia for both brittle and flow failure of soil [13].

$\mathrm{J}$. T. Makanga et al [14] studied the effect of tine rake angle and aspect ratio on soil failure patterns in dry loam soil. Studies were conducted in a laboratory glass-sided soil bin with dry compact loam soil $\left(c=0.02 \mathrm{kPa} . \phi=20^{\circ}\right)$ with the specific objective of observing the effect of flat tine rake angle and aspect ratio on soil failure patterns.

\section{MATHEMATICAL MODEL FOR A SINGLE SHANK}

The shank is the primary tool of cutting the earth; it's used in many applications whatever it's military or civilian. It's widely used in the agricultural application, and in the construction equipment as an auxiliary attachment that used for cutting of the earth, e.g. Bulldozer, grader.... etc.

To calculate the resistance forces acing on the shank, the equilibrium equations of forces acting on the soil wedge are applied, i.e. the summation of the forces acting on the soil wedge will be equal to zero. 


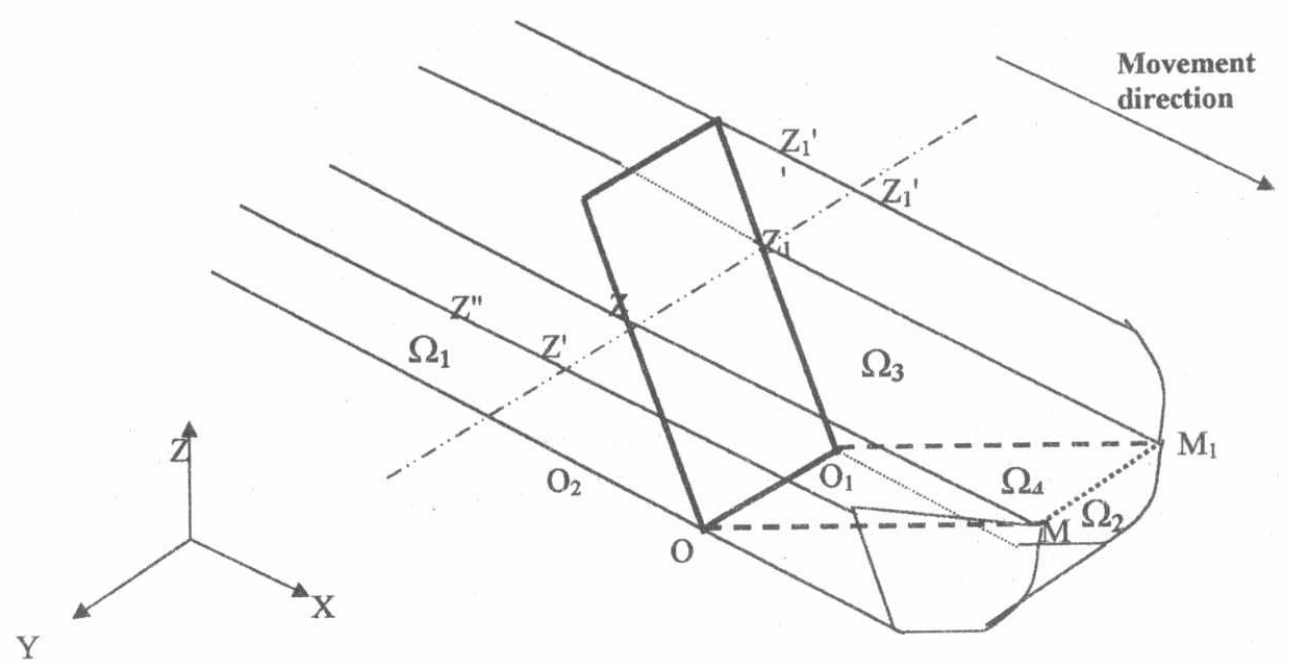

Fig.1. Zones of soil sections and deformation flow during earth cutting using a single shank.

For developing the mathematical model which describes the single shank, the following assumptions are taken into consideration:

1- the rupture surface is plane

2- constant steady speed of operation

3- parts of soil in the soil wedge have no acceleration

4- cutting edge is a flat part

5- the width of the shank is small

As shown in Fig.1 the soil around the shank during ripping is divided into the following zones.

- Lateral rest zone $\left(\Omega_{1}\right)$ which is the zone bounded by the region $\left(\mathrm{O}_{2} \mathrm{O} \mathrm{MZZ} Z^{\prime} Z^{\prime \prime}\right)$ and unbounded in $Y$ direction. The soil velocity in this region equals zero.

- Frontal rest zone $\left(\Omega_{2}\right)$ which is the zone bounded by the region $\left(O M_{1} O_{1} O\right)$ and unbounded in $X$ direction. The soil velocity in this region equals zero.

- Uniform motion zone $\left(\Omega_{3}\right)$ which is the zone bounded by the region (ZOM $\mathrm{M}_{1} \mathrm{O}_{1} \mathrm{Z}_{1}$ ). The velocity of parts in this region is assumed to be uniform and equal to the absolute velocity of soil particles in the zone, $v_{f}$.

- Rupture surface $\left(\Omega_{4}\right)$ which is the zone bounded by the region $\left(O M M_{1} O_{1} O\right)$. It's a part of the uniform motion zone and it makes an angle $\beta$ with the $X$ direction.

\section{Resistance Force Acting On the Shank}

When a single shank of length $a_{1}$ and width equals $b$ is used for cutting the earth at $a$ rake angle $\alpha$ and cutting depth $D_{1}$ which equals $a_{1}$. $\sin \alpha$, a set of resistance forces will be acting on the shank. To determine these forces the region $\left(\Omega_{3}\right)$ should be studied [13]. The forces acting on the shank, Fig. 2 are: 
a) Weight of soil wedge being cut under the ground $\left(m_{1}\right)$

b) Normal force from effects above the surface (W)

c) Friction force between soil and shank surface $\left(F_{f 1}\right)$

d) Adhesion force between soil and shank surface $\left(F_{\mathrm{a} 1}\right)$

e) Friction force on the side of the soil wedge $\left(F_{\mathrm{sf}}\right)$

f) Cohesion force on the side of the soil wedge $\left(F_{s c}\right)$

g) Friction force between soil wedge and ground at the rupture surface $\left(\mathrm{F}_{\mathrm{r}}\right)$

h) Cohesion force between soil wedge and ground at the rupture surface $\left(F_{r c}\right)$

i) Normal force on the rupture surface $(Q)$

j) Shank force acting on the cutting wedge $(P)$

Taking into consideration the Coulomb's earth pressure theory the shank force acting on the cutting wedge $(P)$ will make an angle with the direction normal to the shank edge and its point of application is at a vertical distance equals to $0.34 a_{1} \sin \alpha$ from the bottom of the shank.

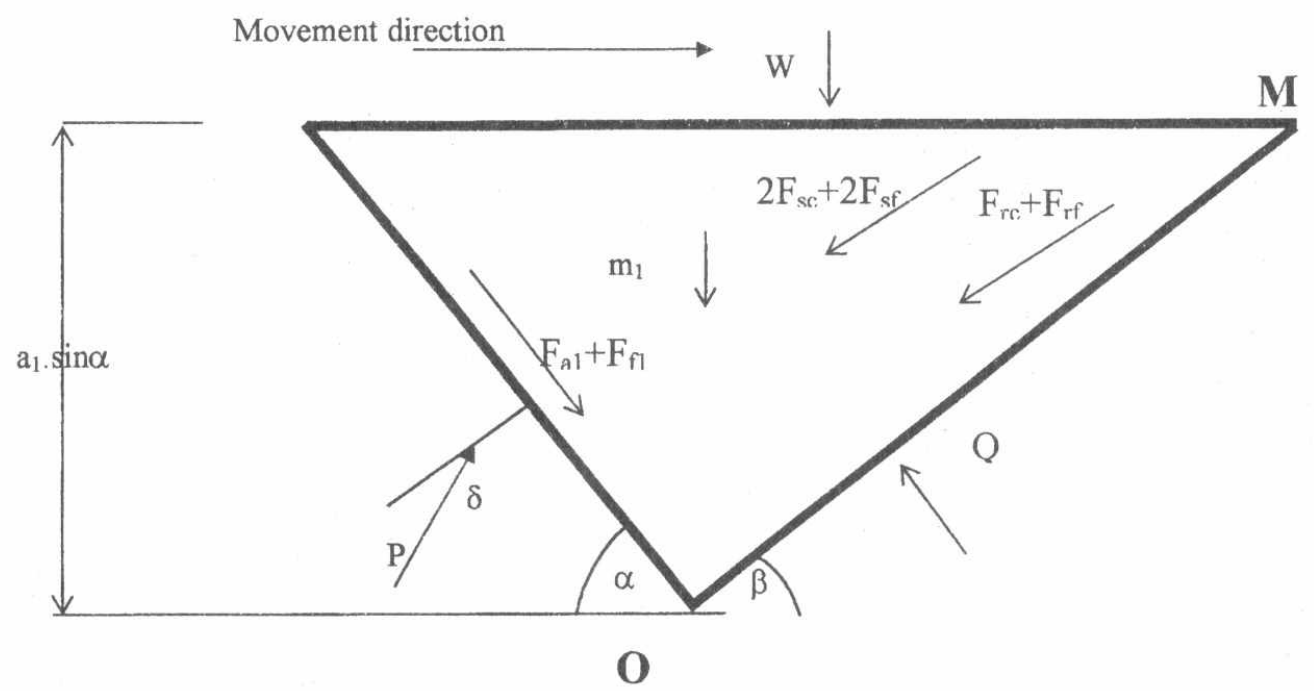

Fig.2. Force analysis under the earth due to earth cutting

by a single shank

\section{Force Analysis and Calculation}

The directions of forces acting on the soil wedge are summarized in Table 2. 
Table 2. under ground forces and their lines of actions

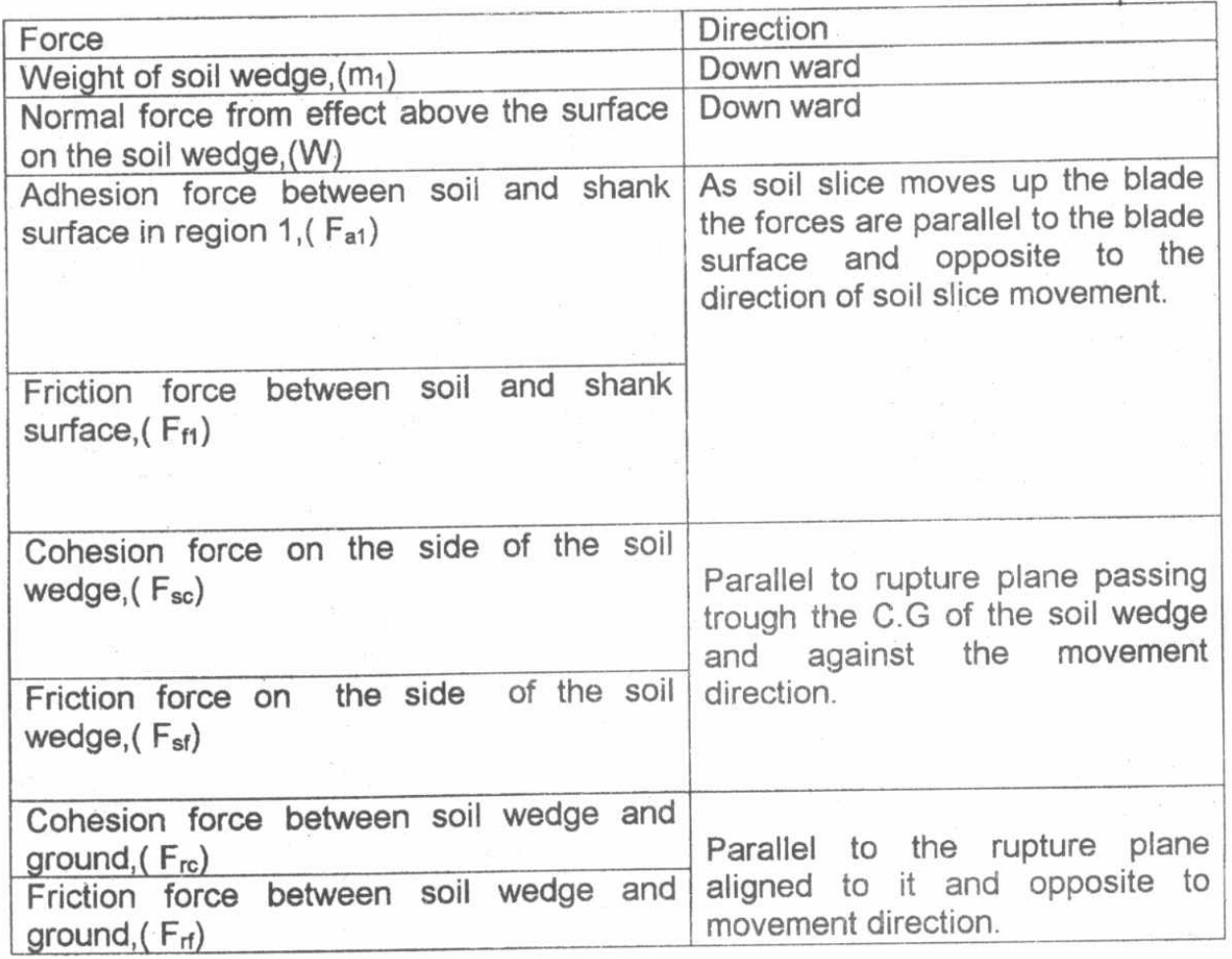

\section{Calculations of Forces Acting on the Soil Wedge}

- Weight of soil wedge being cut under the ground, $m_{1}$ $m_{1}=0.5 \gamma_{0} \cdot b \cdot D^{2}(\cot \alpha+\cot \beta)$

- $\quad$ Friction force between soil and shank surface, $F_{f 1}$

Because soil is sliding over the blade with a relatively high speed, therefore to determine $F_{f 1}$ the following relation which is given by 12 ] will be applied: $f_{p}=C_{a}+A_{a} \cdot \ln v_{e}+\sigma_{n} \cdot \tan (\delta)$ where

$\begin{array}{ll}C_{a} & \text { soil metal adhesion, kpa } \\ f_{b} & \text { soil metal friction stress, kpa } \\ A_{a} & \text { speed effect coefficient of adhesion } \\ V_{e} & \text { sliding speed, } \mathrm{m} / \mathrm{s} \\ \sigma_{n} & \text { normal pressure on the cutting blade, kpa } \\ \delta & \text { Angle of soil metal friction }\end{array}$

let $\mathrm{P}^{\prime}$ be the normal pressure caused by the vertical forces on the shank Hence $\mathrm{P}^{\prime}=\left(\mathrm{W}+\mathrm{m}_{1}\right) / \mathrm{b} \cdot(\mathrm{ZM})$ 
But the normal pressure $P^{\prime}$ creates $F_{1}$ which is a vertical force on the horizontal projection of the shank surface, hence to calculate $F_{n}$ which cause $\left(\sigma_{n}\right)$ to occur over the shank $F_{1}$ should be calculated as follow:

$$
\begin{aligned}
& P^{\prime}=\frac{F_{1}}{b \cdot(O Z) \cdot \cos \alpha} \\
& \therefore \mathrm{F}_{1}=\left(\mathrm{W}+\mathrm{m}_{1}\right) \cdot \frac{\cot \alpha}{\cot \alpha+\cot \beta} \\
& \therefore \sigma_{n}=\frac{F_{n}}{b \cdot a_{1}}
\end{aligned}
$$

where, $\sigma_{n}$ normal pressure on the cutting blade.

$F_{f 1}=f_{p}$. Frictional area between soil and shank surface.

As shown in Fig. 3 particles inside the wedge of soil have an absolute velocity $v_{f}$ which caused by the operating speed of the blade, and the velocity of sliding of the soil on the blade, $v_{e}$.

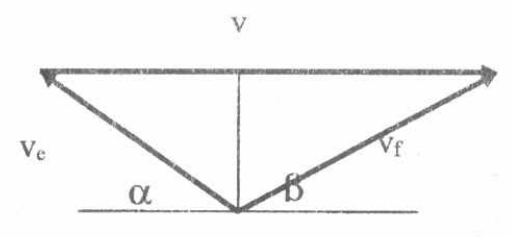

Fig .3. velocity diagram of a soil particle sliding on the blade

Therefore fthe operating speed of the blade will be:

$v=v_{e} \cos \alpha+v_{f} \cos \beta$

Substituting in equation (2) by equations (3), (4) and (5) yields,

$$
F_{f 1}=b \cdot a_{1}\left(\left[C_{a}+A_{a} \cdot \ln \frac{v \cdot \sin \beta}{\sin (\alpha+\beta)}\right] * 1000+\frac{\left(W+m_{1}\right) \cdot \cot \alpha \cdot \cos \alpha \cdot \tan \delta}{b \cdot a_{1} \cdot \cot (\alpha+\cot \beta)}\right)
$$

Adhesion force between soil and shank surface, $F_{\mathrm{a} 1}$

$F_{a 1}=A_{d} \cdot b \cdot a_{1}$

- Friction force on the side of soil wedge, $F_{s f}$

$F_{\text {sf }}=G \cdot \tan \phi$

where... $\mathrm{G}=$ (lateral pressure on the side of soil wedge). (Side area of the wedge)

$\phi \ldots$ soil internal friction angle in degrees.

" Cohesion force on the side of soil wedge, $F_{\mathrm{sc}}$

$F_{\mathrm{sc}}=\mathrm{C}$. side area of the soil wedge 
where

C is the cohesion of uncut soil, $\mathrm{N} / \mathrm{m}^{3}$

$F_{s c}=\frac{C}{2} \cdot(\cot \alpha+\cot \beta) \cdot\left[2 a_{1} D \sin \alpha-a_{1}^{2} \sin ^{2} \alpha\right]$

- Friction force between soil wedge and ground at rupture plane, $F_{\mathrm{rf}}$

$F_{\text {if }}=Q \cdot \tan \phi$

where, $Q \quad$ is the normal force on the rupture plane of the soil wedge.

- Cohesion force between soil wedge and ground at rupture plane, $F_{\mathrm{rc}}$

$\mathrm{F}_{\mathrm{rc}}=\mathrm{C}$. area of rupture plane

$F_{r c}=\frac{C \cdot b \cdot D}{\sin \beta}$

\section{Resultant Force Acting on the Soil Wedge:}

Studying the wedge as a free body diagram note that $F_{\mathrm{sc}}$ and $\mathrm{F}_{\mathrm{sf}}$ are multiplied by two due to its generation from the two sides.

$$
\begin{aligned}
& P_{x}=Q \cdot \sin \beta+\left(2 \cdot F_{s c}+2 \cdot F_{s f}+F_{r f}+F_{r c}\right) \cos \beta-\left(F_{a 1}+F_{f 1}\right) \cdot \cos \alpha \\
& P_{z}=-Q \cdot \cos \beta+\left(2 \cdot F_{s c}+2 \cdot F_{s f}+F_{r f}+F_{r c}\right) \sin \beta+\left(F_{a 1}+F_{f 1}\right) \cdot \sin \alpha+W+m_{1}
\end{aligned}
$$

Therefore

$P=\frac{\left(2 F_{s c}+2 F_{s f}+F_{r c}\right) \cdot \cos \phi-\left(F_{a 1}+F_{f 1}\right) \cdot \cos (\alpha+\beta+\phi)+\left(W+m_{1}\right) \cdot \sin (\phi+\beta)}{\sin (\alpha+\delta+\phi+\beta)}$

\section{Verification of the Single Shank Mathematical Model}

First, a mathematical model of a single shank of width (b) cutting the earth at an angle of cutting $(\alpha)$ with a cutting depth (D) and cutting velocity (v) was developed, then it was simulated by a computer program (SHANK) which was created using a Professional mathematical package.

The program (SHANK) was verified using the published results of the cutting of sand using narrow blades [15]. The operating conditions and the soil properties were published which enable the verification of the program simulating our developed mathematical model. 


\section{Verification results:}

A comparison is held between the results of the (SHANK) program and the published experimental results [15]. The deviation between them is calculated as shown in the Table 3:

Table 3. Program SHANK verification

\begin{tabular}{|c|c|c|c|c|c|c|c|}
\hline \multicolumn{8}{|c|}{ Sand: $D=5 \mathrm{~cm}, \phi=35, \delta=23, C=0.00232 \mathrm{~kg} / \mathrm{cm}^{2}, \gamma=0.00153 \mathrm{~kg} / \mathrm{cm}^{3}$} \\
\hline \multirow{2}{*}{$\begin{array}{c}\text { Case } \\
\text { number }\end{array}$} & \multicolumn{4}{|c|}{ Published operating conditions [8] } & \multirow{2}{*}{$\begin{array}{c}\text { Published } \\
\text { data [8] } \\
\text { Draft force } \\
\text { (N) }\end{array}$} & \multirow{2}{*}{$\begin{array}{l}\text { (SHANK) } \\
\text { results }\end{array}$} & \multirow{2}{*}{$\begin{array}{c}\text { Deviation } \\
(\%)\end{array}$} \\
\hline & $\begin{array}{c}\alpha \\
\text { (deg.) }\end{array}$ & $\mathrm{b}(\mathrm{cm})$ & $\mathrm{B} / \mathrm{D}$ & $\begin{array}{c}v \\
(\mathrm{~cm} / \mathrm{s})\end{array}$ & & & \\
\hline 1 & \multirow{3}{*}{90} & 5 & 1 & 39 & 27.5 & 30.145 & 8.77426 \\
\hline 2 & & 15 & 3 & 36 & 55 & 60.157 & 8.57257 \\
\hline 3 & & 25 & 5 & 35 & 80 & 86.224 & 7.21841 \\
\hline 4 & \multirow{4}{*}{60} & 1.25 & 0.25 & 30 & 7.5 & 7.848 & 4.43425 \\
\hline 5 & & 5 & 1 & 25 & 15 & 17.25 & 13.0435 \\
\hline 6 & & 15 & 3 & 22 & 30 & 33.759 & 11.1348 \\
\hline 7 & & 25 & 5 & 23 & 55 & 61.715 & 10.8807 \\
\hline 8 & \multirow{4}{*}{30} & 1.25 & 0.25 & 23 & 5 & 5.582 & 10.4264 \\
\hline 9 & & 5 & 1 & 17 & 10 & 10.643 & 6.04153 \\
\hline 10 & & 15 & 3 & 17 & 25 & 28.15 & 11.1901 \\
\hline 11 & & 25 & 5 & 16 & 35 & 39.627 & 11.6764 \\
\hline
\end{tabular}

\section{Where:}
$\alpha \quad$ rake angle from the blade with the horizontal
$\gamma \quad$ soil density
D cutting depth
b tool width
$\delta \quad$ soil metal friction angle
C soil cohesion coefficient
\$ soil internal friction angle

The deviation between the mathematical model results and the experimental data (relative error) was calculated. 


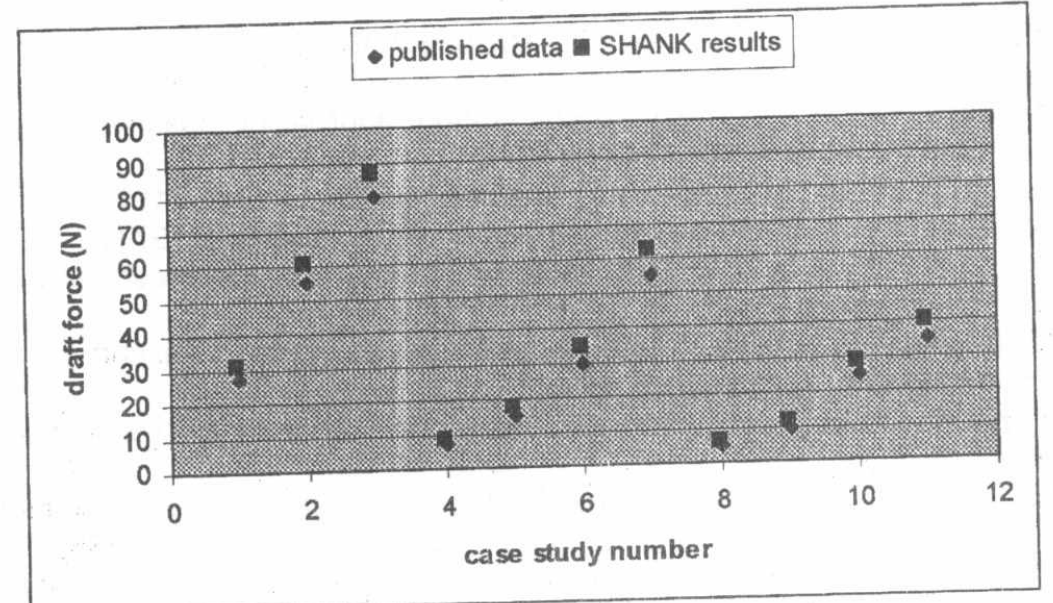

Fig.4. The comparison between the published experimental results and the "SHANK" results.

Fig. 4 clears the relation between the results got by the SHANK program and the results published by the paper to be verified. The deviation between the two results is acceptable putting into consideration the highly nonlinear behavior of the soil.

Results of the "SHANK " program are very close to the published results taking into consideration the accompanied published data about the operating conditions, tool geometry, and soil parameters.

It can be noticed from the results that the deviation between the experimental data and the "SHANK" results is generally increased with the increasing of cutting velocity while all other operating conditions are constant due to the no acceleration assumption, but this has no effect on the program usability in application because of the decreased operating velocity during cutting.

The maximum deviation is acceptable putting into consideration the high nonlinearity behavior of soil.

\section{CONCLUSION}

A mathematical model was developed for predicting resistance forces exerted on the single shank during cutting the earth based on the blade geometry parameters, operating conditions and soil parameters. The comparison between the published results and those predicted by "SHANK" showed that this model can be applied to predict resistance forces exerted upon the single shank during cutting the earth with an acceptable deviation putting into consideration the highly nonlinear behavior of soil. 


\section{REFERENCES}

[1] R.K.KEPNER, ROY BAINER, AND E.L.BARGER."Principles of farm machinery", $2^{\text {nd }}$ edition. AVI publishing company (1971)

[2] C.L.NALEZNY, Analysis of upward soil cutting. Journal of logistics and ground vehicle ASAE, Vol.4, pp.2465 -2471, (1971)

[3] W.F.BILLOTA, et all, Up ward cutting vibratory plowing. Paper 710729 presented at SAE farm, construction and industrial machinery meeting, (1971)

[4] YOTARO HATMURA and KENJI CHIJIIWA, analysis of the mechanism of soil cutting. Bulletin of the JSME, Vol.19, No.137, (1976)

[5] R.N.YONG and A.W.HANNA, Finite element analysis of plane soil cutting. Journal of Terramechanics, Vol.14, No.3, pp.103 - 125, (1977)

[6] M.SPEKTOR, Principles of soil tool interaction. Journal of Terramechanics, Vol.18, No.1, pp.51-65, (1981)

[7] M.SPEKTOR and M.KATZ, Experimental study of frontal resistance forces in soil cutting. Journal of Terramechanics, Vol.22, No.3, pp.127 - 133, (1985)

[8] W. C. SWICK and J. V. PERUMPRAL, A model for prediction soil-tool interaction. Journal of Terramechanics, Vol.25, No.1, pp.43 -56, (1988)

[9] S.B.RICHEY et all, The use of three dimensional computer graphics to design moldboard plough surface. J. Agric. Engng Res., 43, 245 - 258, (1989)

[10] D.C.SUMINISTRADO, M.KOIKE, T.KONAKA, S.YUZAWA, and I.KUROISHI, A model to determine the trajectory of soil motion on a moldboard plow surface. Journal of Terramechanics, Vol.27, No.3, pp.207 - 218, (1990)

[11] L.CHI and R.L.KUSHWAHA, A non-linear 3-d finite element analysis of soil failure with tillage tools. Journal of Terramechanics, Vol.27, No.4, pp.343 - 366, (1990)

[12] YAU YUSU and ZENG DECHAO, Investigation of the relationship between soil metal friction and sliding speed. Journal of Terramechanics, Vol.27, No.4, pp.283 - 290, (1990)

[13] ZENG DECHAO and YAO YUSU, A dynamic model for soil cutting by blade and tine. Journal of Terramechanics, Vol.29, No.3, pp.317 -327, (1992)

[14] J.T.MAKANGA, V.M.SALOKHE, and D.GEE-CLOUGH, Effect of tine rake angle and aspect ratio on soil failure patterns in dry loam soil. Journal of Terramechanics, Vol.33, No.5, pp.233 - 252, (1996)

[15] E. Mckyes and O.S.Ali, The cutting of soil by narrow blades. Journal of Terramechanics, Vol.14, No.2, pp.43 -58, (1977) 